\title{
Factors Influencing Patients to Make the Decision to Discharge Themselves Against Medical Advice at Tertiary Hospitals: A Cross-Sectional Study
}

\author{
Malak AL Sharif \\ King Fahad Medical City \\ Aeshah Alatawi \\ King Fahad Medical City
}

Abdulhadi M. Alqahtani ( $\triangle$ Ph.Abdalhadi@gmail.com )

King Fahad Medical City https://orcid.org/0000-0002-6377-7138

\section{Mohammed Alufi}

Imam Muhammad bin Saud Islamic University: Imam Muhammad Ibn Saud Islamic University

\section{Faisal Alghamdi \\ King Fahad Medical City}

\section{Original Research}

Keywords: Against medical advice, DAMA, discharge, factor, Saudi Arabia

Posted Date: September 9th, 2021

DOI: https://doi.org/10.21203/rs.3.rs-876315/v1

License: (9) This work is licensed under a Creative Commons Attribution 4.0 International License. Read Full License 


\section{Abstract}

\section{Background:}

DAMA is defined as any instance when a patient wants to leave the hospital against the managing physician's decision. This study aimed to identify the most common factors that influence patients to decide to choose DAMA.

\section{Results:}

Between March and April 2021, 510 responses were collected from participants and included in the analysis. Most of the study participants (31.4\%) were over the age of 54 . Our findings showed that $12.5 \%$ of our participants have had taken discharge against medical advice in the past.

\section{Conclusion:}

The long wait time to be seen by a physician was the major factor that forced patients to leave the emergency department against medical advice.

\section{Background}

Discharge against medical advice (DAMA) is defined as any instance when a patient wants to leave the hospital against the managing physician's decision.(1) The release may be initiated by the patient, their relatives in an adult patient with competence problems, or by the parents in a child's case. DAMA is a concern for physicians because it disrupts their interactions with the patient and leads to frustration.(2) DAMA has also been associated with adverse health outcomes and increased healthcare costs.(3)

According to our literature review, patients' reasons for leaving against medical advice include family obligations and financial responsibility. Long waiting times and crowding in the emergency department (ED) are also linked to leaving without being seen by a medical provider, rather than going against medical advice.(4)

DAMA is of great concern to many hospital managers and has a wide range of prevalence in the United States. Some studies claim a prevalence of $1-2 \%$ among general hospital admissions, though in one study from Spain, which included general hospital admissions, the prevalence rate was $0.34 \% .(1,5)$

According to the American College of Emergency Physicians and others, AMA discharges are high-risk situations that can result in malpractice lawsuits. They highly advise that all AMA discharges be carefully documented in the ED chart; every chart should show that the patient knows his or her diagnosis, treatment options, alternative therapies, and the potential repercussions of not following the suggested course of action. Furthermore, the chart should state that no patient should be signed out unless they are deemed competent. After departure from the ED, each patient should receive an equal chance for proper medical follow-up.(6) 
Predictors of DAMA, such as younger age, male sex, substance abuse, psychological disorders, and a lack of health insurance have been reported in the literature.(7) DAMA exposes the patient to the risk of an insufficiently treated medical problem, which could very easily lead to re-admission and extended morbidity-something that could happen in the next few days to weeks-and it may lead to a longer length of hospital stay for any readmission. $(6,8)$

Choi et al. suggested that DAMA patients be closely monitored via telephone consultations or by a primary physician or nurse's visit to check their condition, preferably within one week of DAMA. Such approaches can potentially have a big influence on improving patient outcomes, especially in low-income areas. These findings underline the need for more effective healthcare policies that cover the continuum of care after discharge.(9)

A study conducted in Saudi Arabia discovered a significant association between age and DAMA. DAMA was more likely to occur among younger patients; this is consistent with the findings of other studies. A study at Princess Nourah Bint Abdulrahman University assessing the demographic factors of DAMA from the ED was the first of its kind conducted in Saudi Arabia (10). The researchers recommended conducting further studies to investigate the risk factors for DAMA. The present study aimed to determine the most common factors that influence patients to decide for DAMA at a large referral tertiary hospital operated by the Ministry of Health in Riyadh.

\section{Methods}

\section{Study design/setting}

We conducted a descriptive, cross-sectional analysis using self-administered questionnaires in both Arabic and English. We aimed to document the opinions of patients about the most common factors that would prompt them to DAMA. The study took place in the ED of King Fahad Medical City (KFMC), a 1,200-bed tertiary medical center in Riyadh and one of the largest referral medical centers in Saudi Arabia. All data were collected between March and April 2021.

\section{Inclusion and exclusion criteria}

Using a convenience sampling approach, we invited patients who attended the ED to participate. Eligible participants were at least 18 years old and mentally competent. Patients who had any abnormal mental health status, who were experiencing an acute psychiatric emergency, who were intoxicated, or had a critical illness were excluded.

\section{Questionnaire development}

Previous studies similar to ours were reviewed to determine the most common factors that influence patients to decide on DAMA.(9) Our questionnaire was then modified to fit the study's aim. The questionnaire consisted of 21 questions that were classified into two main sections. The first section consisted of questions about sociodemographic characteristics, such as age, gender, marital status, 
residential area, number of children (if any), educational level and background, where the patient typically seeks medical treatment, and level of health insurance (if any). The second section evaluated the factors that influence patients to decide on DAMA.

A pilot study was carried out among 10 patients at KFMC to ensure good reliability; Cronbach's alpha was 0.735 , indicating the good reliability of our tool, and no substantive changes were made to the questionnaire after the pilot study. The factors' influence domain was assessed using a Likert scale (agree, neutral, and disagree).

\section{Data collection}

To facilitate the data collection, recording, and validation, the questionnaire was administered electronically using Google Forms. Volunteers gathered the replies from the participants. Four volunteers had access to the questionnaire and collected the data; all of them had a medical background (e.g., they were a student or graduate student in medical sciences).

\section{Sample size}

The sample size was calculated using Raosoft(11) and was 362 . We used the universally acceptable confidence interval (Cl) of $95 \%$, with a standard deviation (SD) of 0.5 and a margin of error of $5 \%$. We took a convenience sample size of 500 to account for any dropouts or refusals to participate.

\section{Statistical analysis}

Data analysis was performed using SPSS 25.0 software (SPSS Inc., Chicago, IL, USA). We used a descriptive-frequency test and the chi-square test to determine the intensity of the correlation among independent variables (age, gender, educational level, and marital status) and the factors that influence patients.

\section{Results}

We conducted a pilot study of 10 interviews to assess the validity of our questionnaire and then collected data in March and April 2021. All 500 respondents who signed a consent to participate were included in the final analysis.

Of our sample, in which participants were asked the reasons that might lead to them opting for DAMA, only $64(12.5 \%)$ reported having made a decision for DAMA in the past.

A majority of our study participants were older than age 54 (31.4\%). Males were slightly more common than females, constituting $52.4 \%$ of our sample, and $69 \%$ were married; of these, $63.5 \%$ had children. Most $(72.7 \%)$ of our participants reside in Riyadh city, which meant transportation was not a major issue for most of them. More than $73 \%$ of our sample reported an educational level between middle school and a high school degree. Nearly one-fourth (24.7\%) had medical insurance, and most of our participants reported being treated only in government-run hospitals $76.3 \%$ (Table 1). 


\begin{tabular}{|c|c|c|c|}
\hline & & $n$ & $\%$ \\
\hline \multirow[t]{4}{*}{ Age } & $18-30 y$ & 120 & 23.5 \\
\hline & $31-42 y$ & 107 & 21.0 \\
\hline & $43-54$ & 123 & 24.1 \\
\hline & $>54 \mathrm{y}$ & 160 & 31.4 \\
\hline \multirow[t]{2}{*}{ Gender } & Male & 267 & 52.4 \\
\hline & Female & 243 & 47.6 \\
\hline \multirow[t]{2}{*}{ Marital status } & Single & 158 & 31.0 \\
\hline & Married & 352 & 69.0 \\
\hline \multirow[t]{2}{*}{ Nationality } & Saudi & 482 & 94.5 \\
\hline & Non-Saudi & 28 & 5.5 \\
\hline \multirow[t]{2}{*}{ (If the answer is married), Do you have children } & Yes & 324 & 92.04 \\
\hline & No & 28 & 7.95 \\
\hline \multirow[t]{2}{*}{ Where is your current residence? } & Riyadh & 371 & 72.7 \\
\hline & Outside Riyadh & 139 & 27.3 \\
\hline \multirow[t]{6}{*}{ Educational level } & Uneducated & 70 & 13.7 \\
\hline & Elementary school & 32 & 6.3 \\
\hline & Middle /high school & 192 & 37.6 \\
\hline & Bachelor's degree & 184 & 36.1 \\
\hline & Master's degree & 24 & 4.7 \\
\hline & PhD's degree & 8 & 1.6 \\
\hline \multirow[t]{2}{*}{ Where do you always take your treatment? } & Government hospitals & 389 & 76.3 \\
\hline & Private hospitals & 121 & 23.7 \\
\hline \multirow[t]{2}{*}{ Do you have Medical Insurance? } & Yes & 126 & 24.7 \\
\hline & No & 384 & 75.3 \\
\hline \multirow[t]{2}{*}{ Have you ever discharged against medical advice? } & Yes & 64 & 12.5 \\
\hline & No & 446 & 87.5 \\
\hline
\end{tabular}


A majority of our sample complained of long waiting times before being seen by a physician and a lack of bed availability in relevant wards, with $57.1 \%$ and $52 \%$, respectively, commenting on these issues. We also found that $51.4 \%$ would choose DAMA if the physician or hospital staff showed inappropriate behavior or disrespect to the patient or their relatives. Moreover, $54.5 \%$ stated that the lack of attention from physicians and nurses concerning the patient's needs would be another reason to choose DAMA. Another reason that many (50.4\%) noted for making the decision was the failure to inform the patient or their relatives about their condition.

Interestingly, $44.3 \%$ agreed that they would sign DAMA if they were feeling better, wanted another medical opinion, or if they had relatives at home for which they, the patient, were personally responsible. Only $32.5 \%$ of the participants responded that they 'agree' when asked if the patient's or their relatives' tiredness of the hospital stay would prompt them to sign DAMA. However, $23.9 \%$ agreed to sign DAMA if they had familial or social issues. Among the participants, $36.7 \%$ agreed when asked if they would sign DAMA for an unexpected management plan. By comparison, only $32.9 \%$ of the sample would choose DAMA in response to financial issues (Table 2).

Table 2

Factors influence patients to decide of discharge against medical advice $(n=510)$

\begin{tabular}{|c|c|c|c|c|c|c|}
\hline & \multicolumn{2}{|c|}{ Agree } & \multicolumn{2}{|c|}{ Neutral } & \multicolumn{2}{|c|}{ Disagree } \\
\hline & $n$ & $\%$ & $n$ & $\%$ & $n$ & $\%$ \\
\hline $\begin{array}{l}\text { Inappropriate behavior and disrespect of the physician } \\
\text { or staff to the patient and his relatives }\end{array}$ & 262 & 51.4 & 85 & 16.7 & 163 & 32.0 \\
\hline $\begin{array}{l}\text { Lack of physicians and nurses' attention to the patient } \\
\text { and his relatives (emotionally) }\end{array}$ & 278 & 54.5 & 95 & 18.6 & 137 & 26.9 \\
\hline $\begin{array}{l}\text { Failure to inform the patient or his relatives of his } \\
\text { condition }\end{array}$ & 257 & 50.4 & 95 & 18.6 & 158 & 31.0 \\
\hline Feeling better & 226 & 44.3 & 119 & 23.3 & 165 & 32.4 \\
\hline Patients or their relative's tiredness of hospital stay & 166 & 32.5 & 104 & 20.4 & 240 & 47.1 \\
\hline $\begin{array}{l}\text { Having relatives in home for which patient is personally } \\
\text { responsible }\end{array}$ & 226 & 44.3 & 87 & 17.1 & 197 & 38.6 \\
\hline Having familial or social issues & 122 & 23.9 & 76 & 14.9 & 312 & 61.2 \\
\hline Looking for other medical opinion & 226 & 44.3 & 123 & 24.1 & 161 & 31.6 \\
\hline Unexpected management plan & 187 & 36.7 & 139 & 27.3 & 184 & 36.1 \\
\hline financial issues:(Accommodation, transportation) & 168 & 32.9 & 102 & 20.0 & 240 & 47.1 \\
\hline Long waiting time to be seen by physician & 291 & 57.1 & 65 & 12.7 & 154 & 30.2 \\
\hline Lack of admission beds in relevant wards & 265 & 52.0 & 86 & 16.9 & 159 & 31.2 \\
\hline
\end{tabular}


Our findings indicate that, by far, the major reason why patients opt for DAMA is the long waiting time before being seen by a physician $(P=>0.001)$. We also found a significant association between the decision to choose DAMA and the idea of inappropriate behavior or disrespect by the physician and other staff toward the patient and their relatives $(P=0.024)$. We also found a significant association between DAMA and the failure to inform the patient or their relatives about the patient's condition $(P=0.032)$.

Other significant correlating reasons for choosing DAMA were feelings of tiredness among the patient or their relatives and the presentation of an unexpected management plan $(P=0.010$ and 0.030 , respectively; Table 3). 
Table 3

Association between patients discharged against medical advice and factor influencing patients $(n=510)$

\begin{tabular}{|c|c|c|c|c|}
\hline & & \multicolumn{3}{|c|}{$\begin{array}{l}\text { Have you ever } \\
\text { discharged against } \\
\text { medical advice? }\end{array}$} \\
\hline & & Yes & No & $\begin{array}{l}\mathrm{P}- \\
\text { value }\end{array}$ \\
\hline \multirow[t]{4}{*}{ Age } & $18-30 y$ & 11 & 109 & \multirow[t]{4}{*}{0.066} \\
\hline & $31-42 y$ & 9 & 98 & \\
\hline & $43-54$ & 23 & 100 & \\
\hline & $>54 \mathrm{y}$ & 21 & 139 & \\
\hline \multirow[t]{2}{*}{ Gender } & Male & 40 & 227 & \multirow[t]{2}{*}{0.082} \\
\hline & Female & 24 & 219 & \\
\hline \multirow[t]{2}{*}{ Marital status } & Single & 12 & 146 & \multirow[t]{2}{*}{0.024 * } \\
\hline & Married & 52 & 300 & \\
\hline \multirow[t]{6}{*}{ Educational level } & Uneducated & 9 & 61 & \multirow[t]{6}{*}{0.861} \\
\hline & $\begin{array}{l}\text { Elementary } \\
\text { school }\end{array}$ & 4 & 28 & \\
\hline & $\begin{array}{l}\text { Middle } \\
\text { /high } \\
\text { school }\end{array}$ & 22 & 170 & \\
\hline & $\begin{array}{l}\text { Bachelor's } \\
\text { degree }\end{array}$ & 25 & 159 & \\
\hline & $\begin{array}{l}\text { Master's } \\
\text { degree }\end{array}$ & 4 & 20 & \\
\hline & $\begin{array}{l}\text { PhD's } \\
\text { degree }\end{array}$ & 0 & 8 & \\
\hline \multirow{3}{*}{$\begin{array}{l}\text { Inappropriate behavior and disrespect of the } \\
\text { physician or staff to the patient and his relatives }\end{array}$} & Agree & 39 & 223 & \multirow[t]{3}{*}{0.024 * } \\
\hline & Neutral & 14 & 71 & \\
\hline & Disagree & 11 & 152 & \\
\hline \multirow{3}{*}{$\begin{array}{l}\text { Lack of physicians and nurses' attention to the } \\
\text { patient and his relatives (emotionally) }\end{array}$} & Agree & 41 & 237 & \multirow[t]{3}{*}{0.092} \\
\hline & Neutral & 13 & 82 & \\
\hline & Disagree & 10 & 127 & \\
\hline
\end{tabular}

* The significant p-value 


\begin{tabular}{|c|c|c|c|c|}
\hline \multirow{3}{*}{$\begin{array}{l}\text { Failure to inform the patient or his relatives of } \\
\text { his condition }\end{array}$} & Agree & 42 & 215 & \multirow[t]{3}{*}{$0.032 *$} \\
\hline & Neutral & 9 & 86 & \\
\hline & Disagree & 13 & 145 & \\
\hline \multirow[t]{3}{*}{ Feeling better } & Agree & 31 & 195 & \multirow[t]{3}{*}{0.743} \\
\hline & Neutral & 13 & 106 & \\
\hline & Disagree & 20 & 145 & \\
\hline \multirow{3}{*}{$\begin{array}{l}\text { Patients or their relative's tiredness of hospital } \\
\text { stay }\end{array}$} & Agree & 29 & 137 & \multirow[t]{3}{*}{0.010 * } \\
\hline & Neutral & 16 & 88 & \\
\hline & Disagree & 19 & 221 & \\
\hline \multirow{3}{*}{$\begin{array}{l}\text { Having relatives in a home for which the patient } \\
\text { is personally responsible }\end{array}$} & Agree & 26 & 200 & \multirow[t]{3}{*}{0.093} \\
\hline & Neutral & 17 & 70 & \\
\hline & Disagree & 21 & 176 & \\
\hline \multirow[t]{3}{*}{ Looking for another medical opinion } & Agree & 28 & 198 & \multirow[t]{3}{*}{0.985} \\
\hline & Neutral & 16 & 107 & \\
\hline & Disagree & 20 & 141 & \\
\hline \multirow[t]{3}{*}{ Unexpected management plan } & Agree & 33 & 154 & \multirow[t]{3}{*}{0.030 * } \\
\hline & Neutral & 14 & 125 & \\
\hline & Disagree & 17 & 167 & \\
\hline \multirow{3}{*}{$\begin{array}{l}\text { financial issues:(Accommodation, } \\
\text { transportation) }\end{array}$} & Agree & 20 & 148 & \multirow[t]{3}{*}{0.880} \\
\hline & Neutral & 12 & 90 & \\
\hline & Disagree & 32 & 208 & \\
\hline \multirow[t]{3}{*}{ Long waiting time to be seen by a physician. } & Agree & 51 & 240 & \multirow{3}{*}{$<.001 *$} \\
\hline & Neutral & 3 & 62 & \\
\hline & Disagree & 10 & 144 & \\
\hline \multirow[t]{3}{*}{ Lack of admission beds in relevant wards. } & Agree & 37 & 228 & \multirow[t]{3}{*}{0.360} \\
\hline & Neutral & 12 & 74 & \\
\hline & Disagree & 15 & 144 & \\
\hline
\end{tabular}




\section{Discussion}

DAMA continues to be a large healthcare problem, constituting a major adverse effect on healthcare systems and patient care. DAMA exposes patients to the risk of untreated medical problems, an increased rate of re-admission, and an extended period of recovery and/or morbidity.(6)

Some studies have shown that DAMA is a major strain on healthcare systems and a direct cause of wasted resources. Incurred costs due to DAMA over a 5-year period are estimated to be nearly \$3 billion. (12) The calculated costs due to DAMA are $56 \%$ higher than those expected from a patient's initial hospitalization.(1) This increase in cost could be secondary to several reasons, such as a longer readmission period, double care by physicians and nurses, and extra work-ups on the patient due to care needed to treat complications that may have occurred.

Only $12.5 \%$ of our participants reported having ever signed a DAMA, but this was much higher than our calculated ED DAMA rate in the past year (2020). Still, it was less than the average of $13.2 \%$, derived from three studies published in Iran.(13-15)

In this cross-sectional study, and in contrast to what we expected, we found that educational level has no impact on a patient's decision to sign DAMA. We also found that the majority of our participants who have signed a DAMA were over the age of 43 , which is in contrast to a studies conducted in Pakistan.(16, 17)

Our findings indicate that gender is not a major factor that influences patients' decisions related to DAMA, unlike other studies that showed a significant male predominance. $(13,17,18)$ Meanwhile, marital status was found to be a factor associated with DAMA $(p=0.024)$, which is compatible with the study conducted in Iran.(13)

We were surprised to find that the major factor that would influence our patients to choose DAMA was a long time spent waiting to be seen by a physician, with a p-value of 0.001 , followed by the tiredness related to the hospital stay $(p=0.010)$. Followed by inappropriate behavior and disrespect by staff $(p=$ 0.024), an unexpected management plan and a failure to inform the patient or their relatives about their condition came next, with p-values of 0.030 and 0.032 , respectively. These findings correlate well with findings from other studies. $(19,20)$

Concerns about the lack of available beds in relevant wards was not significant in our study $(p=0.360)$, which could be due to the availability of private rooms and good accommodation in the ER and the same standard of care provided there as in the wards.

Regarding other factors, such as physicians' and nurses' attention to the patient and their relatives' emotional support, financial issues, looking for another medical opinion, having relatives at home for which the patient is personally responsible, feeling better, and educational level, we noted only insignificant correlations with DAMA decisions. This was in contrast to other studies, where financial concerns and insurance had a significant effect. $(9,18,19)$ 


\section{Limitations}

The study was conducted at one site, which may not reflect the true range of impressions and opinions of all citizens of Saudi Arabia.

\section{Implications}

Identifying the factors that influence patients to sign a DAMA is vitally important for decision-makers at the Ministry of Health. Once identified, they can devise action plans and intervention strategies to help healthcare workers provide high-quality care to the patients. They can also help to prevent the waste of healthcare systems' resources.

\section{Conclusion}

A long wait time before being seen by a physician was the major factor that prompts patients to discharge themselves from a hospital against medical advice.

\section{Recommendations}

Our recommendation for future study is to conduct qualitative interviews with patients and healthcare providers to explore in greater depth the factors that lead to DAMA actions and develop proper solutions to reduce and avoid DAMA decisions. The implementation of a new form or method for use at Saudi hospitals to capture all the reasons for DAMA at a national level would also facilitate studies of the phenomenon in the future.

We also recommend mandatory communication skills courses for all physicians during their training. Future studies should also assess emergency doctors' opinions regarding DAMA actions.

\section{Abbreviations}

DAMA

Discharge Against Medical Advice.

ED

Emergency Department.

AMA

Against medical advice.

KFMC

King Fahad Medical City.

$\mathrm{Cl}$

Confidence Interval.

SD

Standard Deviation. 
SPSS

Statistical Package for the Social Sciences.

\section{Declarations}

\section{Ethics approval and consent to participate}

This study was conducted in accordance with the Declaration of Helsinki. Permission to conduct this study was obtained from the institutional review board at KFMC (project No. 21-105). Electronic informed consent was provided by each participant before they answered the questionnaire. Participants received no compensation for their participation in the study.

\section{Consent for publication}

Not applicable

\section{Availability of data and materials}

Not applicable

\section{Competing interests}

The authors declare that they have no competing interests

\section{Funding}

Not applicable

\section{Authors' contributions}

MS: Study design, Data collection, Writing. $A A$ : Study design, Data collection, Writing. $A Q$ : Study design, Data analysis, Writing. MA: Data collection and mangment. FG: Writing and critical revision of the manuscript.

\section{Acknowledgements}

The authors would like to thank the Research Center at King Fahd Medical City, Riyadh, for their valuable support in the preparation of this manuscript. Also, the authors would like to thank our data collectors' team Albandri A. Almutairi, Amnah A Hamami and Rawan S Almutairi.

\section{References}

1. Alfandre DJ. "I'm going home": Discharges against medical advice. Mayo Clinic Proceedings. 2009. 2. Jeremiah J, O’Sullivan P, Stein MD. Who leaves against medical advice? J Gen Intern Med. 1995. 
3. Aliyu ZY. Discharge against medical advice: sociodemographic, clinical and financial perspectives. Int J Clin Pract. 2002.

4. Ding R, Jung JJ, Kirsch TD, Levy F, McCarthy ML. Uncompleted Emergency Department Care: Patients Who Leave against Medical Advice. Acad Emerg Med. 2007.

5. Duñó R, Pousa E, Sans J, Tolosa C, Ruiz A. Discharge against medical advice at a general hospital in Catalonia. Gen Hosp Psychiatry. 2003.

6. Shirani F, Jalili M, Asl-E-Soleimani H. Discharge against medical advice from emergency department: Results from a tertiary care hospital in Tehran, Iran. Eur J Emerg Med. 2010.

7. Adebowale Adefemi S. The Rate, Reasons and Predictors of Hospital Discharge against Medical Advice among Inpatients of a Tertiary Health Facility in North-Central Nigeria. Am J Heal Res. 2015.

8. Anis AH, Sun H, Guh DP, Palepu A, Schechter MT, O'Shaughnessy MV. Leaving hospital against medical advice among HIV-positive patients. CMAJ. 2002.

9. Choi M, Kim H, Qian H, Palepu A. Readmission rates of patients discharged against medical advice: A matched cohort study. PLoS One. 2011;6(9).

10. El-Metwally A, Suliman Alwallan N, Amin Alnajjar A, Zahid N, Alahmary K, Toivola P. Discharge against Medical Advice (DAMA) from an Emergency Department of a Tertiary Care Hospital in Saudi Arabia. Emerg Med Int. 2019.

11. Raosoft. inc. Raosoft Sample size calculator. Online. 2004.

12. Mohseni M, Alikhani M, Tourani S, Azami-Aghdash S, Royani S, Moradi-Joo M. Rate and causes of discharge against medical advice in Iranian hospitals: A systematic review and meta-analysis. Vol. 44, Iranian Journal of Public Health. 2015.

13. Ashrafi E, Nobakht S, Safi Keykaleh M, Kakemam E, Hasanpoor E, Sokhanvar M. Discharge against medical advice (DAMA): Causes and predictors. Electron Physician. 2017;9(6).

14. Vafaee-Najar A, Ebrahimipour H, Meraji M, Hooshmand E, Nezamdoust F, Molavi-Taleghani Y, et al. Factors Associated with Discharge of Children from Hospital Against Medical Advice (AMA) at Doctor Sheikh Pediatric Hospital (DSPH) in Mashhad: 2011-2013. World J Med Sci. 2014;11(2).

15. Karimi S, Saravi B, Farahabbadi E, Zamanfar D, Fallah M, Abokheily M. Studying the Rate and Causes of Discharge Against Medical Advice in Hospitals Affiliated to Mazandaran University of Medical Sciences. Mater Socio Medica. 2014;26(3).

16. Hayat AA, Ahmed MM, Minhas FA. Patients leaving against medical advice: An inpatient psychiatric hospital-based study. J Coll Physicians Surg Pakistan. 2013;23(5).

17. Brook M, Hilty DM, Liu W, Hu R, Frye MA. Discharge Against Medical Advice From Inpatient Psychiatric Treatment: A Literature Review. Psychiatr Serv. 2006;57(8).

18. Bahadori M, Raadabadi M, Salimi M, Ravangard R. Discharge against medical advice: a case study in a public teaching hospital in Tehran, Iran in 2012. Glob J Health Sci. 2013;5(6).

19. Oyira EJ, Mgbekem M, Edet OB. Factors associated with discharge against medical advice among patients in University Of Calabar Teaching Hospital Calabar (UCTH). Glob J Pure Appl Sci. 
2016;22(1).

20. Dubow D, Propp D, Narasimhan K. Emergency department discharges against medical advice. J Emerg Med. 1992;10(4). 